\title{
Mass Transport Improvement by PEF - Applications in the Area of Extraction and Distillation
}

\author{
Claudia Siemer, Stefan Toepfl and Volker Heinz \\ German Institute of Food Technologies
}

Germany

\section{Introduction}

Mass transport processes in the food industry are mostly based on the diffusion of soluble products out of food tissue. The main barrier for the diffusion is the biological membrane separating the inner cellular material from the outside. A rupture of the membrane results in an enhanced diffusion rate resulting in a higher yield of the product located in the cell. Most methods used for disintegration of cellular material are mechanical, chemical or thermal based treatments. A new promising technique for cell rupture is the application of pulsed electric fields (PEF). The product is treated with pulses of microseconds at a high electric field strength. The electric field affects the cell membrane of the biological tissue in order to increase the permeability resulting in pore formation. Pore formation facilitates the diffusion process. Moderate PEF settings are used to achieve a disintegration of the cellular material. Some researchers define a moderate PEF treatment by applying a field strength of 0,5 to $1,0 \mathrm{kV} / \mathrm{cm}$ and treatment times in a range of 100 and $10.000 \mu \mathrm{s}$. The same effects were obtained by other researchers using electric field strengths of 1 to $10 \mathrm{kV} / \mathrm{cm}$ and shorter treatment times in the range of 5 to $100 \mu$ s (Schilling et al., 2007; Corrales et al., 2008; López et al., 2009).

It has been reported that PEF induces an increase of the mass transfer process resulting in a higher extraction of different intracellular materials, such as sucrose from sugar beet, betalains from red beetroot or polyphenols from grapes during the wine production. An increase in the extraction yield of juices from different fruits and vegetables has also been noted. The drying process can also be improved by PEF application. The reduction in the drying time yields a better end product quality. For example an accelerated osmotic dehydration and drying was reported for different fruits and vegetables, such as potatoes and pepper. An improvement of the distillation processes by PEF, for example distillation of rose oil was also reported.

The following chapter describes in detail the effect of PEF on the mass transfer and the related application fields.

\section{Principle of action of cell disintegration using PEF technology}

The application of PEF using short pulses of a high voltage affects the membrane of a cell resulting in a permeabilisation of the biological membranes. 
The membrane acts as a semi permeable barrier for the intra- and extracellular transport of ions and macromolecules. The membrane can be considered as a capacitor filled with dielectric material of low electrical conductance and a dielectric constant in the range of 2 (Castro et al., 1993; Barbosa-Cánovas et al., 1999). The accumulation of the free charges in- and outside the cell leads to the formation of a concentration gradient, which is called trans membrane potential. The resulting voltage varied in a range from 20 to $50 \mathrm{mV}$ (Wilhelm et al., 1993).

The exposure of the cell to an electric field with a specific intensity causes a movement of the charges along the electric field lines, which results in an induction of an additional potential. The trans membrane potential increased due to the electric field up to a value of $1 \mathrm{~V}$ (Zimmermann et al., 1976; Weaver 2000). The action of polarizing the cell is illustrated in Fig. 1.

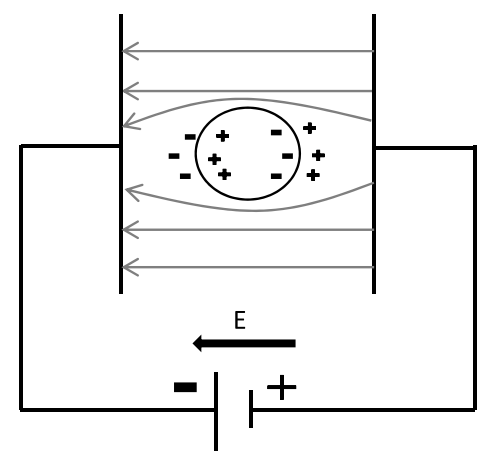

Fig. 1. Induction of cell polarization caused by PEF application (adapted from (Dimitrov 1995))

The polarization of the membrane is related to an increase of conductivity of the membrane in the range of more than $1 \mathrm{~S} / \mathrm{cm}^{2}$ (Dimitrov 1984; Tsong 1991; Wilhelm et al., 1993). Due to this increase the resistance of the membrane decreases and results in dramatic change in permeability for potassium and sodium (Pliquett et al., 2007). The higher permeability leads to a dielectric breakdown of the cell, which occurs at different electric potentials depending on the electrical pulse duration (Dimitrov 1984).

Due to the polarization of the membrane, which is related to the movement of free charges, forms electro compressive forces causing the local dielectric rupture of the membrane. Dielectric rupture is the formation of pores and a drastic increase of permeability, which can be termed as dielectric breakdown (Zimmermann et al., 1976). This electro mechanical process is still the most accepted explanation for describing the effect of applying an external electric field on biological cells. Other theories describe the membrane as a viscoelastic model with fluctuating surfaces. The external applied electric field induces reorientation and deterioration of the membrane molecules resulting in pore formation and also the expansion of the pores leading to mechanical breakdown of the membrane (Dimitrov 1984).

The electric breakdown occurs if the applied electrical potential exceeds a critical value, which is termed the critical potential. Temperature, cell size and shape as well as medium and process conditions are influencing factors for the critical potential. The pulse duration 
as a process condition leads to a lower critical potential if long pulse durations are applied (Dimitrov 1984).

The induced pore formation by the external electric field leads to an increase of the permeability of the membrane. Due to the intensity of the pulses reversible and irreversible pores can be formed. Reversible pores are formed, applying less energy than the critical potential. Using that intensity of the electric pulses stress reactions in plant cells can be induced and the production of secondary metabolites can be stimulated (Schilling et al., 2007). If the intensity of the electric pulses exceeds the critical potential irreversible pores are formed, which causes lethal cell damages. This potential can be applied to inactivate pathogen and non-pathogenic microorganisms or to facilitate the mass transfer and to improve the diffusion of intra- and extracellular liquids. The result of a facilitated mass transfer and improved diffusion is a facilitated distillation process due to the disintegration of cellular material by PEF (Dobreva et al., 2010).

Consequently applying PEF using intensities higher than the critical value two different effects can be observed. On the one hand inactivation of microorganisms (Heinz et al., 2001; Toepfl et al., 2007) and on the other hand the cell disintegration (Angersbach\&Heinz 1997; Angersbach et al., 2000). The difference between these two effects is the applied intensity of the electric field and the specific energy, which represents two of the main process parameters of a PEF treatment. The electric field strength is defined as the electric potential difference $(\mathrm{U})$ for two given electrodes in space divided by the distance $(\mathrm{d})$ between them, separated by a non-conductive material (Zhang et al., 1995). The specific energy describes the intensity of the treatment with high intensity pulses and is expressed in $\mathrm{kJ} / \mathrm{kg}$. Because of the small size of the microorganisms and the composition of their membranes, a high energy input is required for a successful inactivation (Glaser et al., 1988).

For a microbiological inactivation of different vegetative microorganisms, which has been widely demonstrated by various researchers (Álvarez et al., 2000; Toepfl et al., 2007) an electric field strength of 15 to $20 \mathrm{kV} / \mathrm{cm}$ and a specific energy of 40 to $1000 \mathrm{~kJ} / \mathrm{kg}$ is required. In contrast for a disintegration of cellular material lower values for electric field strength (range of 0,7 to $3 \mathrm{kV} / \mathrm{cm}$ ) and a specific energy (range of 1 to $20 \mathrm{~kJ} / \mathrm{kg}$ ) is required (Corrales et al., 2008). The comparison of the values shows less energy is required for cell disintegration.

\section{Determination of cell disintegration index}

The application of PEF induces a polarization of the cellular membrane resulting in an increased trans membrane potential. The increase leads to a rapid electrical breakdown and to local structural changes in the membrane. The result of the applied external electric field is the formation of pores related to an increase of permeability of the membrane. A permeabilisation influences the diffusion processes, for example increasing the extraction yield and shortening the distillation time. To make the best use of the permeabilisation, a maximum of cell disintegration is required. But it has to be noted that cell permeabilisation by PEF leads to a softer structure. An optimum for the PEF settings (process parameters) has to be defined as for some liquid solid separation techniques a too soft texture may be limiting. Up to now different methods are available to measure the permeability of membranes. Microscopic methods can be 
used when the analysed tissue was stained. It is also possible to measure the content of the extracted material (sugar, ions) (Angersbach\&Heinz 1997). Mostly these two methods are not exact enough to determine the disintegration of biological membranes. A better method for determining the cell disintegration is the electrical method based on measuring the frequency dependent conductivity.

An external electric field induces a polarization of the membranes. A result of the polarization is an increase of the membrane current and a simultaneously decrease of the resistance of the membrane, which corresponds to an increase of the conductivity (Angersbach et al., 2000). The increase of the conductivity up to $5 \mathrm{mS}$ in less than $5 \mu$ s (Angersbach et al., 2000) can be measured and be set in relation to the conductivity of intact membrane. Consequently analyzing the frequency dependent conductivity offers the possibility to estimate the amount of intact cellular material. The relation of the conductivity of the intact and the disintegrated cells is termed as the cell disintegration index $Z_{p}$. The cell disintegration index allows an exact definition of the amount of ruptured cellular material. If there is no difference between the conductivity of the untreated and PEF treated cell membrane, the $Z_{p}$ value is 0 and the cell can be defined as an intact cell. In contrast to that a $Z_{p}$ value of 1 indicates the maximum of cell disintegration due to the PEF treatment (Angersbach\&Heinz 1997).

The frequency dependent conductivity allows a detection of product properties. Fig. 2. illustrates an example of conductivity of various treated and untreated tissues at different frequencies.

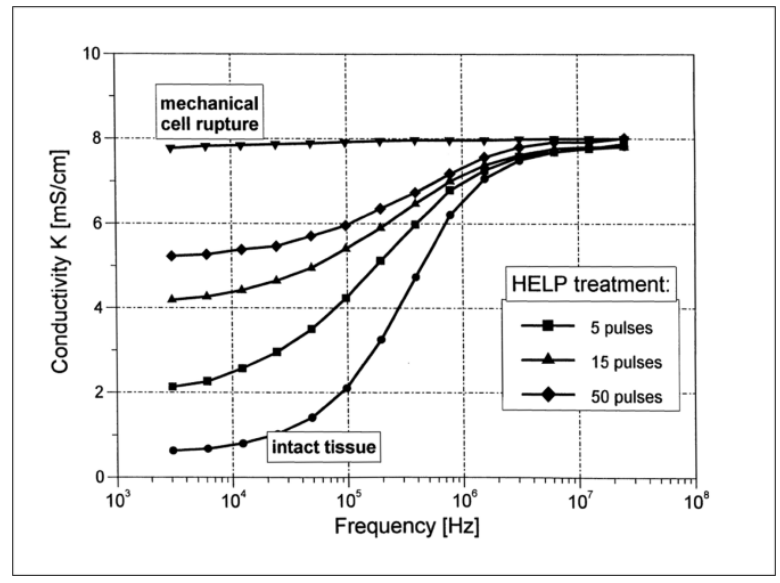

Fig. 2. Measured conductivity at different frequencies (Knorr\&Angersbach 1998)

As it can be seen in Fig. 2. the conductivity changes with increasing frequency. At low frequency ranges the conductivity of PEF treated cell material and intact tissue is different, because of the capacitive properties of intact tissue. The highest value for conductivity relates to mechanically ruptured cells. From the graph it can also be seen that as the frequency increases, the conductivity of all cellular material reaches the same conductivity value. The reason being the relationship between conductivity and the frequency. At high frequency ranges $(5-10 \mathrm{MHz})$ the cell membranes, whether damaged or not, are not resistant to the electric current (Angersbach\&Heinz 1997; Knorr\&Angersbach 1998). 
Besides the relation between the conductivity and the frequency, the Fig. 2. also displays the impact of pulse number on the effect of the permeabilisation of cellular material. A higher number of applied pulses leads to a higher conductivity, which shows a higher permeabilisation of the membrane (Knorr\&Angersbach 1998). Not only does the number of pulses affect the efficiency of the PEF treatment, the applied electric field strength amplitude also plays a part. Higher electric field strength causes a more rapid dynamics of pore formation and a faster initiation of conductive channels (Angersbach et al., 2000). To compare the relation between number of pulses and electric field strength; typically a lower number of pulses is necessary to reach a high disintegration of cellular material when high electric field strength is applied (Knorr\&Angersbach 1998; Angersbach et al., 2000). The effect of the electric field strength in relation to the permeability of the membrane is illustrated in Fig. 3.

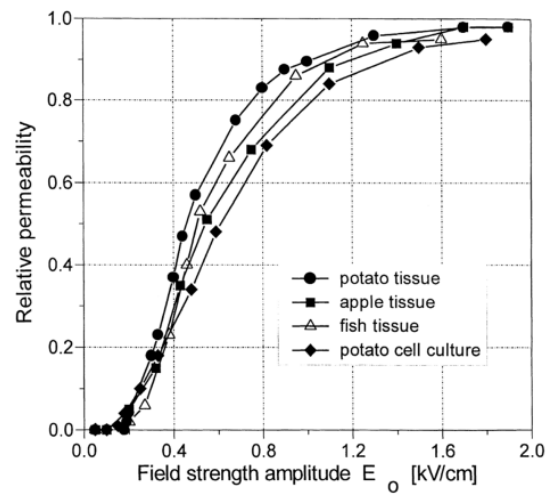

Fig. 3. Relation between the electric field strength amplitude and the relative permeability (Angersbach et al.,2000)

Using low field strength amplitudes no significant differences between the samples were observed, because the electric field strength did not reach the critical value and no electrical breakdown is induced. This phenomenon occurs if the applied field strength is higher than the critical field strength. With increasing electric field strength the relative permeability of the membrane increases up to the maximum, where all cells are disintegrated.

Fig. 3. also displays the dependence of the applied electric field amplitude to the type of product. Four different tissue types (potato-, apple- and fish tissue and potato cell culture) were tested and different values of electric field strength were necessary for a disintegration of these tissues. The reason for this is based on dependence of the membrane to rupture on the trans membrane voltage and the cell size distribution (Angersbach et al., 2000).

By measuring the conductivity the optimum electric field strength can be determined. The aim is to reach a maximum cell disintegration. Lebovka et al. 2002 (Lebovka et al., 2002) detected an electric field strength of $400 \mathrm{~V} / \mathrm{cm}$ for maximum of cell disintegration of apple-, carrot and potato tissue. Comparing these tissues treated with $400 \mathrm{~V} / \mathrm{cm}$ different treatment times are necessary to reach a high cell disintegration. Apple tissue required the highest treatment time and consequently the highest energy consumption in contrast to potato, which has the lowest energy consumption (Lebovka et al., 2002).

In conclusion, by measuring the conductivity changes induced by PEF treatment it is possible to determine the amount of disintegrated cells. 


\section{Influence of PEF on mass transfer}

The application of pulsed electric fields allows a disintegration of cellular material. The result of disintegrated cells is an improved mass transfer, which affects the following processes:

- Dehydration/Freezing

- Extraction

- Distillation

The drying process can be described as a preservation method removing water from food. Water removal, lowers the water activity and increases the shelf life of the products. It can be used as a pre-treatment to improve nutritional, organoleptic and functional properties of the food products (Torreggiani 1993). An important parameter for the drying process is the mass transfer of water. A high mass transfer rate results in a better quality of dried product due to the shortening of the drying time and a reduction in the drying temperature. The drying process can be regarded as a complex process step including momentum, heat and mass transfer. The moisture in food can be classified in two main groups. First the "immobilized" water, which is retained in fine capillaries and is adsorbed at the surface, and second the "free" water, which retains in voids in foods. The drying process is based on the equilibrium of moisture content. The food looses or gains moisture over a period of time to attain a new equilibrium status (Sharma et al., 2000). For drying of heat sensitive products the osmotic dehydration (OD) can be used as a pre-treatment in order to reduce the drying time. Other pre-treatments, like microwave or conventional thermal heating, lead to a thermal destruction of the nutrients and organoleptic quality of the food (Ade-Omowaye et al., 2001).

For this process, food is placed in an osmotic solution resulting in the formation of a water and a solubility gradient across the cell membrane. The cell membrane separates cell content, mostly water, and the osmotic solution. Consequently two fluxes are formed; the water out of the cell and the osmotic solution into the cell. This flux is a mass transfer process and is a function of the difference in chemical potential. Because of the composition of the cell membrane and the better permeability to water, more water is removed from the cell than less solute goes into the cell. The following Figure (Fig. 4.) represents the flux of water and solute in and out the cell (Torreggiani 1993; Sharma et al., 2000).

The OD process depends on different parameters, like concentration of osmotic solution, contact time and process temperature as well as the exposed surface area. The most widespread problem is the simultaneous solute transfer in the food countercurrent to the water flow. This influences the product quality in a negative way resulting in a candy or salty taste of the product, as well as an altered sugar-to-acid ratio. Different kinds of osmotic solutions can be used. The choice depends on parameters, like organoleptic quality, preservative effect and the product taste. Mostly a sucrose solution is used, because it is very effective and convenient. But because of the sweetness the application is limited to vegetables and fruits. The second most used substance for osmotic solutions is sodium chloride.

In comparison to convection drying the OD process uses less energy, because a lower temperature can be used. Due to the reduced temperature, less heat damage is found on the 


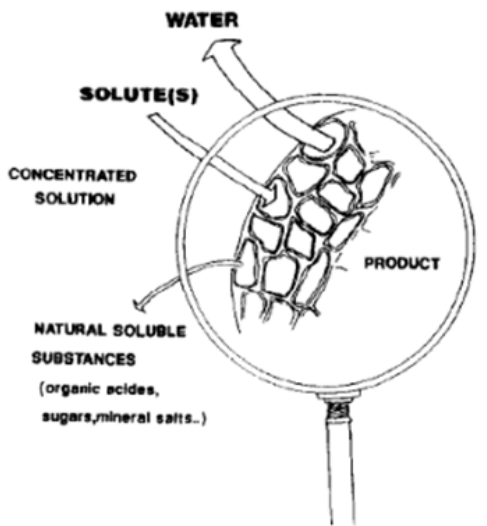

Fig. 4. Mass transfer during OD process (Torreggiani 1993)

product and the high concentration of the osmotic solution prevents discoloration (Torreggiani 1993).

As the OD process is directly dependent on the mass transfer, a PEF treatment can enhance OD. The first time facilitated mass transfer during OD using PEF was reported by Rastogi et al. (Rastogi et al., 1999). Because of the structural changes of the cell membrane due to PEF application, the mass transfer is facilitated (Ade-Omowaye et al., 2001). Consequently a facilitated, fast exit of the water in the osmotic solution is possible, but no solid uptake, because of the selective permeabilisation of the cell membrane (Taiwo et al., 2003). Using PEF before the OD process the drying time can be significantly reduced and a better structural food quality can be obtained.

Different product types were treated with PEF before OD. For example, the pre-treatment of red pepper with PEF shows a facilitated moisture removal and an improvement of the quality of the dried products. Using OD in combination with PEF a preserved color quality of the red pepper could be obtained (Ade-Omowaye 2003). Carrots can also be pre treated with PEF resulting in an increased diffusion coefficient and a reduction of the OD time from $4 \mathrm{~h}$ to $2 \mathrm{~h}$ (Rastogi et al., 1999). The PEF induced enhanced mass transfer depends on the electric field strength and the applied number of pulses (Rastogi et al., 1999). The same reduction in OD was reported (Rastogi et al., 1999; Amami et al., 2007a; Amami et al., 2007b) for the treatment of apple tissue (Amami et al., 2006).

In addition to drying process the freezing process can be regarded as a mass transport dependent preservation method. Suitable products for this type of treatment are fruits (strawberries and raspberries), vegetables (peas, green beans) as well as fish and meat products (Sharma et al., 2000). The process is based on a decrease of temperature under the freezing point and combines the effect of low temperature with the conversion of water into ice (Delgado\&Sun 2001). The advantage of the freezing process is the reduced chemical reactions and the delay of cellular metabolic reactions (Delgado\&Sun 2001).

In general the freezing process can be separated into three main phases. The first phase is called the pre-cooling or chilling phase, where the product is cooled down to the freezing 
point. During the second phase (phase change period) most of the water in the product crystalizes. The final end temperature is reached during the last phase termed as the tempering phase (Delgado\&Sun 2001).

The time, which is required to lower the temperature, is called the freezing time. This time can be predicted with mathematic modeling. Therefore the heat and mass transfer phenomena has to be considered. Two possible models to describe the freezing process are the heat transfer model and coupled heat and mass transfer model. The application of PEF improves the mass transfer. The pre-treatment of potato (Jalté et al., 2009) for example induces a higher freezing rate with a shorter freezing time. Due to PEF treatment the cell membrane gets porous with the result of an enhanced diffusion mass exchange of extracellular and intracellular water as well as a reduced freezing time. Using PEF as a pretreatment can achieve a better quality of the frozen food as smaller ice molecules are also formed. The improved quality can be seen in Fig. 5. The structure and form of the PEF pretreated potato was much better in comparison to the untreated ones.

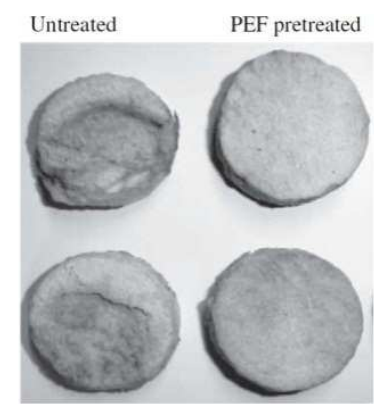

Fig. 5. Pre-treatment of potato discs in comparison to untreated discs after freezing (Jalté et al., 2009)

Besides drying and freezing, PEF treatment influences the extraction process. In general, extraction is a separation process separating a substance from a matrix. Two main extraction processes are liquid-liquid extraction and solid-liquid extraction. In the following the soliliquid extraction is described in detail as well as the impact of PEF on the solid-liquid expression.

The aim of a solid-liquid extraction is the separation of the desired extract located in the solid by using a solvent in which the extract is soluble. Mostly, the extract is located in the pore or cell structure of the solid. This technique has been used a long time for the extraction of plant oils, for example sucrose from sugar beet or tanning- or color extracts. Today the solid-liquid extraction is mostly used for (Bouzrara\&Vorobiev 2003)

- $\quad$ Extraction of fruit juices and vegetable oils

- Production of wine

- Dewatering of fibrous materials (sugar beet)

- Dehydration of organic wastes

The principle of an extraction process is based on the diffusion characteristics of the solid and the solubility of the extract. The solvent is added to the solid and during the extraction 
the extract diffuses from the solid in the solvent. This mass transport from the solid in the solvent follows the diffusion law. After this process a mechanical separation of the solid and liquid is required as well as a separation of the extract and the extraction agent. A facilitated extraction can be reached by chopping or mashing the solid with the result of an increased surface area and shorter capillary ways. Another possibility to increase the extraction velocity is an increase of the concentration gradient. This can be achieved by using a high volume of solvent (Vauck\&Mueller 2000).

As described before the principle of the extraction process is based on the mass transfer of the extract from the solid in solvent. The extract is mostly located in cells, which are surrounded by membranes. Consequently, the amount of compounds released to the solvent depends on the degree of the damaged cellular material. The effect of PEF can be defined as electroporation resulting in a disintegration of cellular material and an improved mass transfer. Regarding the extraction process a facilitated extraction is possible using PEF as a pre-treatment, because the extract can easily diffuse into the solvent. There is no force required to open the cellular material. Using PEF as a pre-treatment, the extraction time can be reduced. The extraction yield can be increased and important quality ingredients can be easily extracted.

PEF can be used for an improved extraction process in different application fields. One example is the extraction of calcium from bones (Yin\&He 2008). There are different methods used for the extraction of calcium from bones, for example boiling or microwave treatment, often leads to negative effects on the product and the extracted concentration is low. Using $\mathrm{PEF}$, the temperature can be reduced and the calcium concentration increased (Yin\&He 2008).

Another example for a solid-liquid expression assisted by PEF treatment is sugar beet. Using PEF as a pre-treatment the extraction time and temperature can be lowered (López et al., 2009) as well as a higher sucrose yield can be obtained (Eshtiaghi\&Knorr 2002; ElBelghiti\&Vorobiev 2004) resulting in more efficient sugar production with lower energy requirements (Lebovka et al., 2007; Loginova et al., 2011). Due to the lower extraction temperature the PEF process offers the possibility to improve the extraction of colorants from red beet root in order to increase the extraction yield and a better stability of the colorants (Fincan et al., 2004; Loginova et al., 2011). An increased juice yield plays an important role in juice industry. In general mechanical, enzymatic or temperature based methods were used to rupture the apple cells for a facilitated extracting, but mostly they lead to a degradation of important juice components as well as a high energy consumption (Toepfl 2006). A PEF treatment of the apples increases the yield from 1,7 to $7,7 \%$ in comparison to an enzymatic treatment (4,2\%) (Schilling et al., 2007) and reduces the energy consumption. Additional the pomace can be used after the treatment for pectin extraction.

Another process limited by mass transfer is the distillation process. In this process a high temperature is applied to the product for a defined time in order to separate two components with different boiling points. The high temperature denatures the cellular material and facilitates the extraction of the product. The high heat load degrades the heat sensitive ingredients minimizing the quality of the product. The membrane of the cells represents a semipermeable barrier through which the desired extract cannot diffuse because of the size. After the cells are ruptured the extract can easily diffuse along the 
concentration gradient. To rupture the cells, PEF can be used. Using PEF a disintegration of the cells could be observed at moderate temperatures. Consequently, the heat load could be minimized and no change of quality of the extract could be detected. In addition to that, the extraction yield could also be increased. In summary, the result of using pulsed electric fields instead of high temperature treatment is a reduced temperature and distillation time. A possible application being the treatment of roses to gain a higher yield of rose oil while reducing the distillation time (Dobreva et al., 2010).

\section{Application}

\subsection{Extraction}

A facilitated extraction of valuable components, like sucrose from sugar beet, red colorants from red beet roots and polyphenols from wine as well as juice from fruits, can be achieved by using PEF as a pre treatment.

The traditional sucrose extraction process is a thermal one treating the cossettes at 70 to $75^{\circ} \mathrm{C}$ for 1 to $1,5 \mathrm{~h}$. The heating process permits a denaturation of the sugar beet cells and facilitates the sugar extraction. This process uses a significant amount of energy and water and assists the growth of spoilage microorganisms. Lopez et al. (López et al., 2009) studied the influence of PEF on the extraction yield dependent on the electric field strength and pulse number as well as temperature. As a result applying 20 pulses with a field strength of $7 \mathrm{kV} / \mathrm{cm}$ allows a temperature reduction from $70{ }^{\circ} \mathrm{C}$ to $40^{\circ} \mathrm{C}$ in a $60 \mathrm{~min}$ extraction process with yield of $80 \%$. The related thermal energy consumption is lowered by more than $50 \%$. In addition the extraction is dependant on the field strength, specific energy as well as temperature and independent from pulse shape and pulse duration (López et al., 2009). Agitation during extraction leads to an increase of the sucrose yield (El-Belghiti\&Vorobiev 2004). In this study the sugar beets were treated with $0,9 \mathrm{kV} / \mathrm{cm}$ and 250 pulses in a cylindrical batch treatment chamber. For an extraction yield of $30 \%$, an extraction time of $120 \mathrm{~min}$ with $100 \mathrm{rpm}$ agitation is required in comparison to $500 \mathrm{~min}$ extraction time without agitation. The sugar extraction process assisted by PEF can be improved by additional agitation, as well as by applying pressure. Using a pressure of $30 \mathrm{MPa}$ during the extraction process the extraction yield can be increased by $20 \%$ (Eshtiaghi\&Knorr 2002).

Besides the yield of the PEF assisted extraction process, the quality of the sucrose was analysed. The treatment of sugar beets with an electric field strength of $0,6 \mathrm{kV} / \mathrm{cm}$ and 500 pulses with a pulse duration of $100 \mu \mathrm{s}$ at $30^{\circ} \mathrm{C}$ leads to comparable results of thermal process at $70^{\circ} \mathrm{C}$ (Loginova et al., 2011).

The thermal treatment at $70{ }^{\circ} \mathrm{C}$ leads to a sucrose content of $14 \%$ and a purity of more than $90 \%$. Equal values have been reached using a PEF treatment at $30{ }^{\circ} \mathrm{C}$. The energy consumption required by PEF treatment is $5,4 \mathrm{kWh} / \mathrm{t}$ versus $46,7 \mathrm{kWh} / \mathrm{t}$ for the thermal treatment. In conclusion, the application of PEF lowers the energy consumption without influencing the sucrose content or the purity of the extracted sucrose solution (Loginova et al., 2011). Increasing the temperature of the PEF treatment leads to a reduction of the required electric field strength without decreasing the important quality parameters. Another study of Loginova et al. (Loginova et al., 2011) shows an increased sucrose content and ${ }^{\circ}$ Brix values of extracted product assisted by PEF in a parallel stainless steel electrode with a gap of $7 \mathrm{~cm}$ applying $0,6 \mathrm{kV} / \mathrm{cm}$ at $50^{\circ} \mathrm{C}$. The end result is a higher purity and 


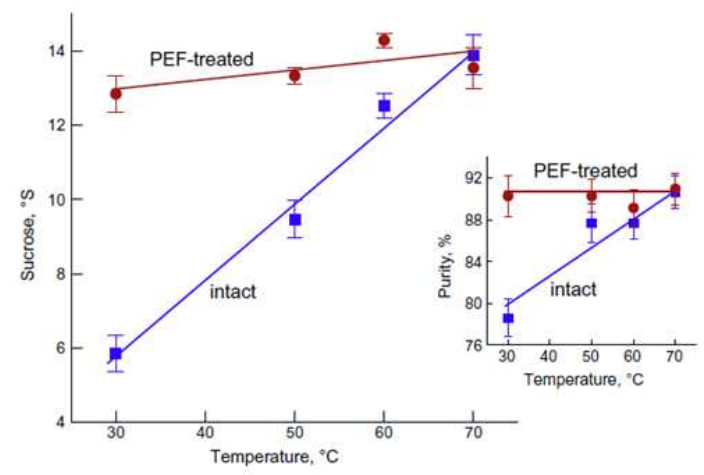

Fig. 6. Influence of temperature and PEF on the sucrose concentration and the purity of the sucrose solution (Loginova et al., 2011)

improved filter capability of the product in comparison to the thermally treated product at $70^{\circ} \mathrm{C}$.

The thermal treatment is dependent on the holding time (equal with treatment time for the extraction process) and aiming on an almost complete thermo-break. The application of PEF reduces the treatment time resulting in a high cell disintegration index of approximately 0,95 in several milliseconds in contrast to a cell disintegration index of 0,85 in more than $100 \mathrm{~s}$ for a thermal treatment. A higher cell disintegration index can be reached by using a higher electric field strength (Lebovka et al., 2007). The researchers Eshtiaghi et al. (Eshtiaghi\&Knorr 2002) indicated a cell disintegration index of approximately 0,7 by treating the slices with an electric field strength of $2,4 \mathrm{kV} / \mathrm{cm}$ and 20 pulses at $20^{\circ} \mathrm{C}$. The same cell disintegration index can be achieved by a heat treatment at $72^{\circ} \mathrm{C}$ for $15 \mathrm{~min}$.

In addition to the extraction of sucrose from sugar beet the extraction of industry relevant colorants from red beet roots can be improved. Red beet concentrate can be used as a food additive to color food. Betalains are the major colorants, and are composed of the red -violet substance betacyanin and the yellow-orange betaxanthin. The main function of betalains beside the color, is antiviral and antimicrobial activity (Azeredo 2009). Most extraction processes contains a thermal treatment leading to a lower extraction yield and high color degradation, because of the sensitivity of the betalains towards high temperature. For example a thermal treatment at $30^{\circ} \mathrm{C}$ for $5 \mathrm{~h}$ leads to a degradation of $20 \%$ of the betalains. In comparison an extraction at $80^{\circ} \mathrm{C}$ for $1 \mathrm{~h}$ results in a complete degradation of the betalains (Loginova et al., 2011). The extraction assisted by PEF lowers the temperature without decreasing the extraction yield and destruction of the color (Fincan et al., 2004; Loginova et al., 2011). The same extraction rate can be achieved using a pre-treatment with PEF at $30^{\circ} \mathrm{C}$ of the red beet using a field strength of $1,5 \mathrm{kV} / \mathrm{cm}$ and 20 pulses with a duration of $100 \mu \mathrm{s}$ in comparison to a thermal treatment at $80^{\circ} \mathrm{C}$ for $40 \mathrm{~min}$ and in addition with less color degradation (Loginova et al., 2011).

Another main product function is the solid-liquid juice extraction process assisted by PEF. The effects of PEF on the extraction of apple juice will be described. The left side of the Fig. 7. below shows a current process for apple juice extraction. 


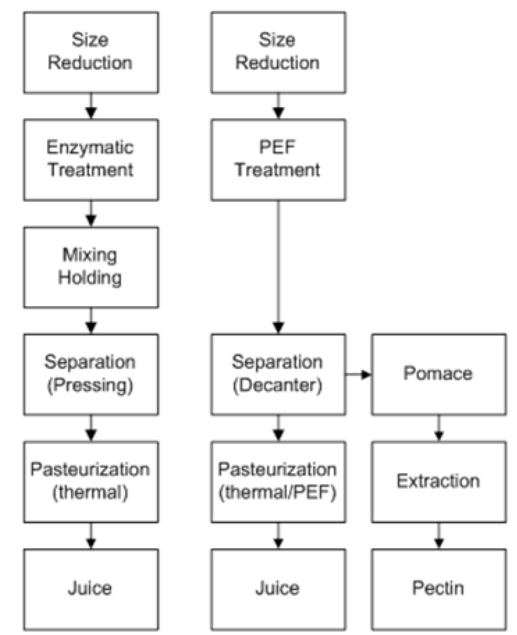

Fig. 7. Left side the traditional apple juice process, right side the process using PEF (adapted from (Toepfl 2006))

The current extraction process contains an enzymatic treatment to rupture the apple cells. This step can be replaced by a PEF treatment (see right side of Fig. 7.) in order to increase the extraction yield without a destruction of the juice quality (Bazhal\&Vorobiev 2000; Bazhal et al., 2001; Toepfl\&Heinz 2011). The extraction yield can be increased to 1,7-7,7 \% using field strengths of 1 and $5 \mathrm{kV} / \mathrm{cm}$ and 1 to $30 \mathrm{~kJ} / \mathrm{kg}$ using a decanter centrifuge. In comparison, an increased extraction yield of $4,2 \%$ can be achieved using enzyme treatment (Schilling et al., 2007). For the enzymatic treatment the apples were treated with a pectolytic enzyme for $1 \mathrm{~h}$ at $30^{\circ} \mathrm{C}$, the pectin is degraded using an enzymatic treatment for increasing the extraction yield. After the PEF treatment, native pectin can be produced from the pomace. An increase of the nutrient content of the juice was not observed (Schilling et al., 2007). Grimi et al. (Grimi et al., 2011) studied the extraction yield, clarity, polyphenol content and the antioxidant activity of the pre-treated apples. Additionally they differ between the treatment of whole apples and sliced apples. Treatment of sliced apples with a field strength of $0,4 \mathrm{kV} / \mathrm{cm}$ and a treatment time of $0,1 \mathrm{~s}$, resulted in a higher extraction yield than the treatment of whole apples using the same conditions. The cell disintegration index, clarity of the juice, polyphenol content and the antioxidant activity showed no difference between the two different apple type treatments.

The studies of Grimi et al. (Grimi et al., 2011) show an increase of the polyphenol content in apple juice in comparison to the non PEF treated sample. Similar results were reported by Puertolas et al. and Corrales et al. (Corrales et al., 2008; Puertolas et al., 2010) studying the extraction of polyphenols from red wine grapes. The polyphenols are the most important components for the color and the quality of the red wine. A rupture of the grape skin, where the polyphenols are located, leads to a release of the polyphenols resulting in a facilitated extraction. A PEF induced cell disintegration using an electric field strength of $3 \mathrm{kV} / \mathrm{cm}$ and $10 \mathrm{~kJ} / \mathrm{kg}$ results in an increase of the phenolic compounds as well as a higher antioxidant content $(7841 \mu$ molTE g-1DM in comparison to $187 \mu$ molTE g-1DM thermal treatment at $70^{\circ} \mathrm{C}$ for $1 \mathrm{~h}$ ) (Corrales et al., 2008). 
The oil extraction process also contains a solid-liquid extraction step, which can be improved by PEF application. Guderjan et al. (Guderjan et al., 2005) studied the effect of PEF on the oil yield of maize and olives. Pulsing the maize with an electric field strength of $0,6 \mathrm{kV} / \mathrm{cm}$ and a specific energy of $0,62 \mathrm{~kJ} / \mathrm{kg}$ at $20^{\circ} \mathrm{C}$ yields an extraction of $43,7 \%$ in comparison to a yield of $23,2 \%$ of the untreated maize. The same effect of increased extraction yield is observed when treating olives with $1,3 \mathrm{kV} / \mathrm{cm}$ and 100 pulses. An increase of $7,4 \%$ with PEF in contrast to an increase of $5,3 \%$ for a heat treatment $\left(50{ }^{\circ} \mathrm{C}\right.$ for $30 \mathrm{~min}$ ) was determined (Guderjan et al., 2005). Beside olive and maize, rape seed can be treated to enhance the extraction yield and the quality of the oil. In that case, an improved oil yield was observed as well as an increase of the polyphenol-, phytosterol and tocopherol content. The rape seeds were pulsed with field strength of $7 \mathrm{kV} / \mathrm{cm}$ and 120 pulses (Guderjan et al., 2007).

\subsection{Distillation}

Distillation is a separation process, where the product is exposed to a defined temperature for a specific time. Because of the different boiling point of the components, a separation of these substances is possible.

The traditional rose oil distillation process is characterized by exposing a product to a high temperature for a defined time. The temperature causes a denaturation of the cell membrane and substances diffuse out of the cells. Due to the temperature sensitivity of the rose oil during the distillation process, the critical threshold should not be exceeded as the quality of the rose oil will be reduced. A lower temperature results in reduced disintegration of the rose cells and in a low extraction yield. To improve the rupture of the cell membrane, the cells can be exposed to pulsed electric fields. The electric field induces a polarization with a resulting breakdown of the cell membrane and an increased permeability. The process can be used for the rose oil production. Dobreva et al. (Dobreva et al., 2010) studied different PEF treatment conditions varying the specific energy and different distillation times. The aim was to detect the influence of PEF on the extraction yield and distillation time.

The PEF treatment was performed in parallel treatment chamber with a gap of $5 \mathrm{~cm}$. The white oil-bearing roses (Rosa alba L.) were pulsed with an electric field strength of $4 \mathrm{kV} / \mathrm{cm}$ and a specific energy of 10 and $20 \mathrm{~kJ} / \mathrm{kg}$ at room temperature. The distillation time using high temperature for cell rupture was $2,5 \mathrm{~h}$. For the analysis the oil yield was determined after 0,5, 1, 1,5 and 2,5 h (Fig. 8.).

After a distillation time of $1 \mathrm{~h}$ equivalent oil yields for the PEF and control samples were found. An increase of energy input from 10 to $20 \mathrm{~kJ} / \mathrm{kg}$ causes an increase of oil yield of $20 \%$. Treating the roses with a specific energy of $10 \mathrm{~kJ} / \mathrm{kg}$, the yield was increased by $35 \%$ compared to the control. In conclusion, using PEF as a pre-treatment the distillation time can be reduced resulting in lower energy consumption and a higher productivity of the distillation process. A higher yield can be achieved by treating the roses with PEF and a specific energy of $10 \mathrm{~kJ} / \mathrm{kg}$ and a distillation time of $2,5 \mathrm{~h}$.

Besides the improvement of yield and the distillation time, the quality of the oil analysis also showed no undesirable changes of any of the essential components in comparison to the reference extraction method. 

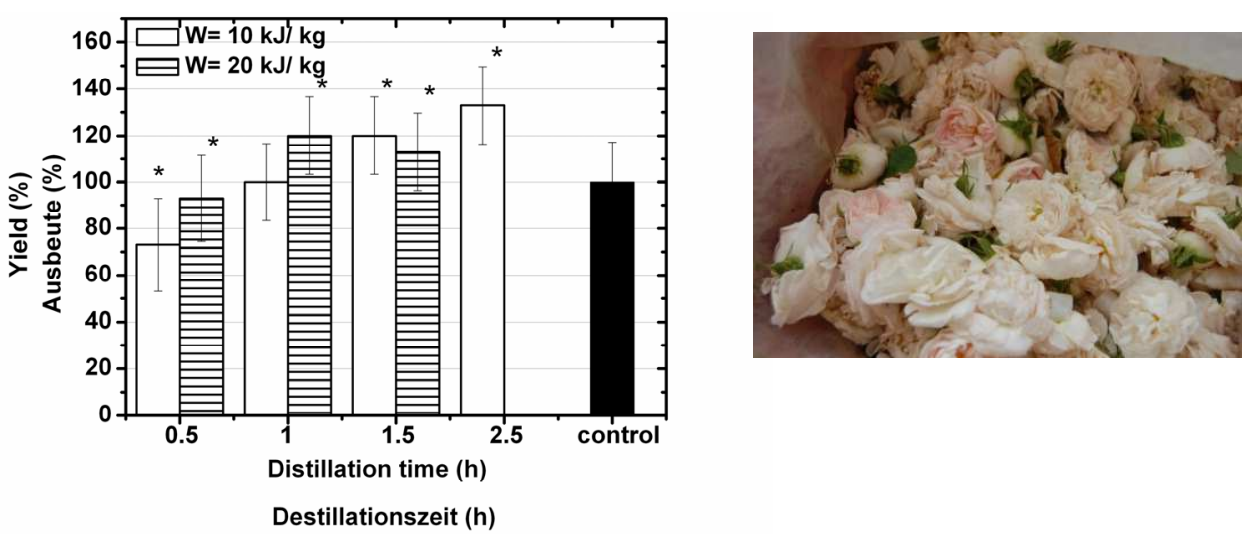

Fig. 8. Oil yield after a PEF pre-treatment of the roses in comparison to untreated after different distillation times (Dobreva et al., 2010)

\subsection{Drying/Freezing}

Drying is regarded to be an important preservation step. Temperature, relative humidity and time are the most important processing paramters. The drying process can be separated into three main parts. The first describes the evaporation from free surface, which is mostly influenced by heat and mass transfer. The second part includes the liquid flow from the capillaries and the third the diffusion of liquid or vapour (Sharma et al., 2000). The mass transfer, which is important for the first step of drying, is determined by the structure of the cellular material. By influencing the structure for example a disintegration of the cells, a facilitated mass transfer can be obtained. A cell disintegration of biological cell membranes can be induced by exposing the material to an electric field. The application of pulsed electric fields induces structural changes that leads to a rapid cellular breakdown and an increased permeability resulting in an enhanced mass transfer. The idea to use the PEF process in order to facilitate the drying process is described by several researchers and food products.

One product example using PEF as a pre-treatment before drying is red pepper. AdeOmowaye et al. (Ade-Omowaye et al., 2000) investigated an increased water loss using the PEF process. For drying, a fluidized bed was used with a temperature of $60{ }^{\circ} \mathrm{C}$ for $6 \mathrm{~h}$. The researchers examined the influence of the electric field strength and pulse number on the efficiency of the drying process. After 1,5 h drying the moisture content of the untreated red pepper sample was $2,06 \mathrm{~kg} / \mathrm{kg}$, of the sample treated with $1 \mathrm{kV} / \mathrm{cm}$ it was $1,45 \mathrm{~kg} / \mathrm{kg}$ and the moisture content of the red pepper sample treated with $2 \mathrm{kV} / \mathrm{cm}$ it was $1,09 \mathrm{~kg} / \mathrm{kg}$. That corresponds to a decrease of moisture of $47 \%$ at the same drying time. In summary an increasing electric field strength leads to a higher reduction of moisture content. In comparison to that shows the pulse number not that high influence so that a high pulse number has only a minimal effect on the electro permeabilisation (Ade-Omowaye et al., 2003). The same effect is reported by Knorr 1998 (Knorr\&Angersbach 1998). Regarding the distillation time, after $3 \mathrm{~h}$ drying the drying rate was not higher as compared to the rate at $1,5 \mathrm{~h}$. The reason for that is based on the fact, that nearly all water was evaporated at that time and the driving force was reduced. 
Besides the use of PEF as a pre-treatment for red pepper, reports have shown that it can be used for treating carrots in order to increase the drying efficiency. Amami et al. (Amami et al., 2007a; Amami et al., 2007b) treated the sliced carrots with an electric field strength of $0,6 \mathrm{kV} / \mathrm{cm}$ and a specific energy of $19 \mathrm{~kJ} / \mathrm{kg}$ as well as a pulse duration of $100 \mu \mathrm{s}$. After the PEF treatment different osmotic dehydration trials were performed to evaluate the influence of salt and sucrose concentration as well as the additional effect of a centrifugal instead of a static osmotic dehydration process. The water loss and ${ }^{\circ}$ Brix of the solution was determined after defined time periods. For the OD process the ratio of carrots to solution was 1:3 and the duration was $240 \mathrm{~min}$ at $20^{\circ} \mathrm{C}$. The water loss of the untreated carrots after $2 \mathrm{~h}$ static OD process was $42 \%$. A pre-treatment of the carrots with PEF induces a water loss of $38 \%$ and a sugar concentration of $45^{\circ}$ Brix. Consequently, the PEF treatment positively affects the mass transfer process. Besides the analysis of the effect of PEF on the water loss, the effect of the addition of sucrose and additional salt concentration was determined. As the sugar concentration is increased, the water loss was also increased. The addition of salt $(\mathrm{NaCl})$ to the sucrose solution leads to different water loss values. An overview of the results is shown in Table. 1.

\begin{tabular}{|c|c|c|}
\hline $\begin{array}{c}\text { Composition of the OD solution } \\
{[\% \text { salt/\%sucrose] }}\end{array}$ & $\begin{array}{c}\text { water loss [\%] } \\
\text { untreated }\end{array}$ & $\begin{array}{c}\text { water loss [\%] } \\
\text { PEF treated }\end{array}$ \\
\hline $0 \% / 65 \%$ & 48,5 & 50 \\
\hline $5 \% / 60 \%$ & 50,9 & 54,6 \\
\hline $15 \% / 50 \%$ & 54,5 & 58,8 \\
\hline
\end{tabular}

Table 1. Water loss of untreated and PEF treated $(0,6 \mathrm{kV} / \mathrm{cm}, 19 \mathrm{~kJ} / \mathrm{kg})$ carrots slices using different salt concentrations for the osmotic solution in a OD process after $4 \mathrm{~h}$ (summarized from (Amami et al., 2007b))

By increasing the salt concentration a higher water loss can be obtained and the water loss can be improved even more by using PEF as a pre-treatment. A higher salt concentration leads to a higher diffusion gradient and combining a higher salt concentration with a PEF process, which induces an improved mass transfer, leads to a better diffusion with regard to the dehydration process. The addition of $\mathrm{NaCl}$ lowers the water activity, which increases the driving force for the drying process. Using a centrifugal OD process the water loss of the untreated carrot slices can be increased from $48,5 \%, 50,9 \%$ and $54,5 \%$ in $0 \% / 65 \%, 5 \% / 60 \%$ and $15 \% / 50 \%$ to $56,5 \%, 58,1 \%$ and $61,9 \%$. As a result, centrifugation leads to an improved OD. The best result for an OD can be reached using PEF, a salt/sucrose solution as osmotic solution and centrifugation. The temperature influence was also evaluated with the result of an improved $\mathrm{OD}$ using $40^{\circ} \mathrm{C}$ in comparison to $20^{\circ} \mathrm{C}$ (Amami et al., 2007a; Amami et al., 2007b). Similar results could be obtained using the PEF pre-treatment of apples. The mass transfer of apples is increased by the PEF treatment (Chalermchat et al., 2010) and the kinetics of water and solute transfer were accelerated during the convective and diffusion stages of OD process (Amami et al., 2006). Also the treatment of strawberries with PEF leads to an improvement of the OD process. Taiwo et al. (Taiwo et al., 2003) treated strawberries placed in tap water in a parallel stainless steel electrode with a gap of $3 \mathrm{~cm}, 5$ pulses with a duration of $350 \mu$ s were applied to the product using an electric field strength of $1,2 \mathrm{kV} / \mathrm{cm}$ and $100 \mathrm{~J} /$ pulse. For the OD different osmotic solutions were tested to find out the best solution with the highest efficiency (Fig. 9.). 


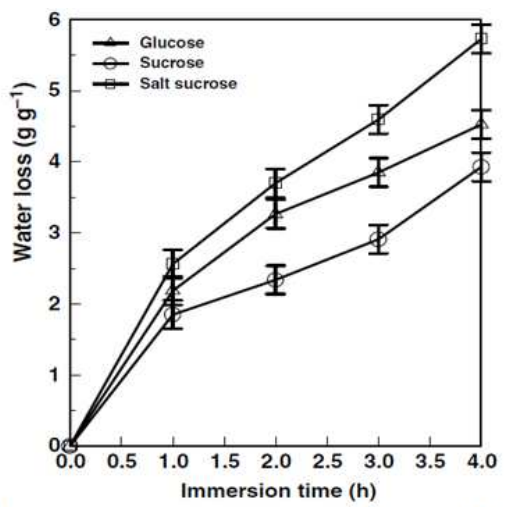

Fig. 9. Extent of water loss from PEF pre-treated strawberries during OD process in different osmotic solutions (Taiwo et al., 2003)

From the above examples it can be said that pre-treatment with PEF increases mass transfer during the OD. When considering different osmotic solutions containing glucose, sucrose or salt/sucrose results show that the salt/sucrose solution shows the best result regarding the water loss.

In addition to PEF treatment of carrots in order to improve the OD, potatoes can also be regarded as suitable products for a PEF pre-treatment. The application of PEF on potatoes with an electric field strength of $1,5 \mathrm{kV} / \mathrm{cm}$ induces an enhanced drying process, because of the disintegration of the potato cells induced by PEF. The comparison of a freeze dried potato without PEF and a PEF freeze dried potato shows less structure damage (Lebovka et al., 2007). Besides the structure also the diffusion characteristics in potatoes can be improved using PEF. For example a PEF treatment using $1,5 \mathrm{kV} / \mathrm{cm}$ and 20 applied pulses leads to a release of glucose and fructose, which are precursors for Maillard reaction, and a facilitated uptake of sodium chloride (Janositz et al., 2010). A reduced browning and acrylamide formation has been reported (Lindgren et al., 2002). A comparison of the treatment of potatoes and apples shows different diffusion coefficients during OD for these two different food products. The treatment of apples showed an increase of diffusion coefficient. The treatment of potatoes by PEF showed that the diffusion coefficient could be improved. The reason for this difference is based on the morphological structure of potato and apple. The tissue of potato is more tightly packed in contrast to the apple tissue (Arevalo et al., 2004).

Using PEF as a pre-treatment the drying and freezing rate can be improved. With increasing cell disintegration the freezing rates increased. Regarding the freezing process cellular water flows easily out of the cell and ice nucleation outside the cell starts. SEM pictures show the impact of PEF on the freezing process (Jalté et al., 2009).

The untreated potato cells show perturbation of the original polyhedral arrangement of the cells and also disrupted cell walls. The structure of PEF treated potato indicates a structural damage in order to a partial destruction of the polyhedral shape. Fig. 10. (right) shows voids, which can be explained by the formation of ice crystals outside the cell (Jalté et al., 2009). 

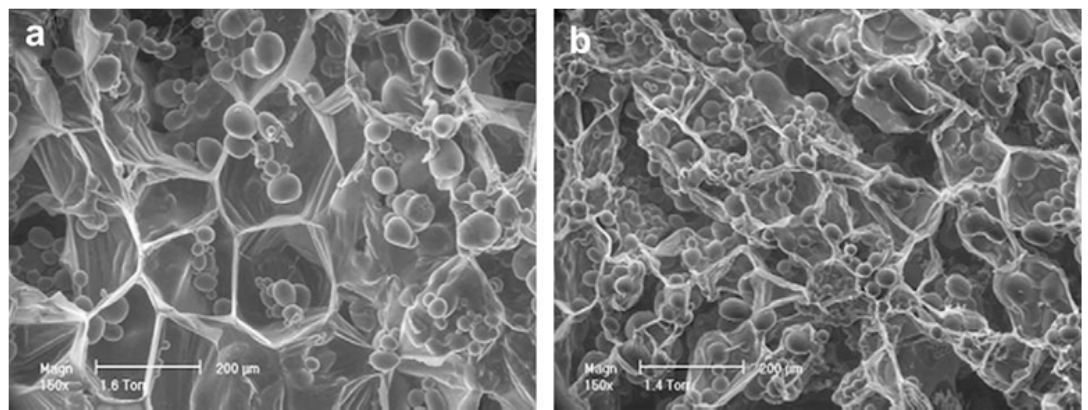

Fig. 10. Cellular structure of a untreated (a) and a PEF treated (b) potato after freeze and thaw process (Jalté et al., 2009)

\subsection{Process and equipment design}

Most of the PEF applications described as a pre-treatment in order to increase the extraction yield, to decrease the distillation time and/or process temperature, were performed with discontinuous PEF systems using a parallel or cylindrical electrode configurations for the treatment chambers. A parallel electrode configuration of the treatment chamber allows a homogenous electric field distribution. All tests with the different food types and systems were performed on a lab-scale. Toepfl et al. (Toepfl\&Heinz 2011) studied a scale up from pilot plant to production scale for the apple juice production. They showed nearly the same increase of juice yield compared to the lab scale trials without influencing the taste or nutritional content. An increase of total acids, glucose, fructose and saccharose as well as total polyphenols was observed. Because of the high quality of the juice and the accordance of all quality parameters within the Europrean Code of Practice for Fruit Juices (AIJN 1996), the production including the PEF process step is equal to the common used process without PEF (Schilling et al., 2007; Toepfl\&Heinz 2011).

A continuous treatment up to an industrial scale has been realized by DIL. At the moment three different systems are available for laboratory scale, semi-industrial scale and industrial scale. The $5 \mathrm{~kW}$ system has a maximum voltage of $30 \mathrm{kV}$ and maximum current of $200 \mathrm{~A}$. The pipe diameter ranges from 10 to $30 \mathrm{~mm}$. Due to the small pipe diameter it is not possible to treat tubers or whole fruits. An increased pipe diameter can be used in $30 \mathrm{~kW}$ systems with a maximum voltage of $30 \mathrm{kV}$ and a maximum current of $700 \mathrm{~A}$. The pipe diameter can be increased up to $100 \mathrm{~mm}$ and for the application cell disintegration the capacity is $10.000 \mathrm{~kg} / \mathrm{h}$. A further increase of capacity up to $50.000 \mathrm{~kg} / \mathrm{h}$ can be realized using the $80 \mathrm{~kW}$ systems with a maximum voltage of $60 \mathrm{kV}$ and a maximum current of $5.000 \mathrm{~A}$. The pipe diameter of these systems is in range of $200 \mathrm{~mm}$, as an alternative belt type chambers can be used. At a belt width of $1 \mathrm{~m}$ the processing capacity can be up to $50.000 \mathrm{~kg} / \mathrm{h}$.

The $30 \mathrm{~kW}$ system and the belt system and a PEF system with a pipe diameter of $50 \mathrm{~mm}$ are shown in Fig. 11.

The PEF treatment consumes less energy compared to for example thermal treatments. For the treatment of sliced apples, the energy consumption is $12,5 \pm 0,5 \mathrm{~kJ} / \mathrm{kg}$ and for whole apples $7,9 \pm 0,4 \mathrm{~kJ} / \mathrm{kg}$ (Grimi et al., 2011). The typical energy requirement is in a range of 


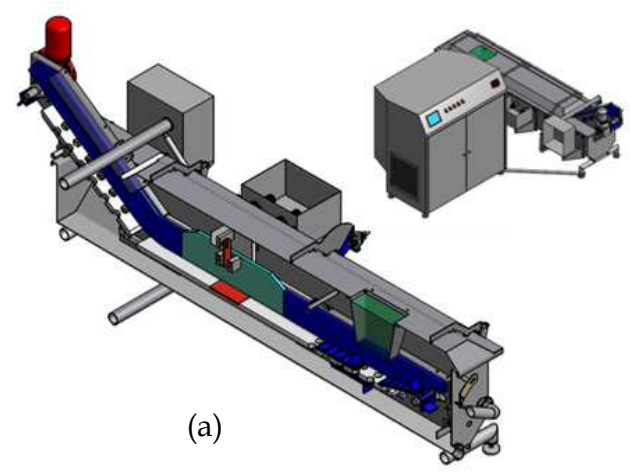

(b)

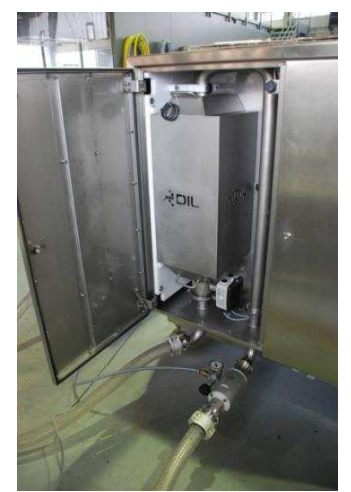

Fig. 11. (a) $30 \mathrm{~kW}$ belt system for the treatment of tubers or whole fruits, (b) PEF system with a pipe diameter of $50 \mathrm{~mm}$

$3 \mathrm{kWh} /$ ton for a complete tissue disintegration. Compared to other cell disruption methods (mechanical: 20-40 kJ/kg; enzymatic: $60-100 \mathrm{~kJ} / \mathrm{kg}$; heating, freezing/thawing: $>100 \mathrm{~kJ} / \mathrm{kg}$ ) the energy consumption is very low (Toepfl 2006). For tissue softening, where a lower extent of cell disintegration is required, the typical specific energy input for a PEF treatment is in a range of $1 \mathrm{~kJ} / \mathrm{kg}$. The same effect can be observed during the sugar extraction process. More than $50 \%$ of the thermal energy can be saved using a PEF treatment (temperature: $40^{\circ} \mathrm{C}$ ) instead of a thermal treatment $\left(70^{\circ} \mathrm{C}\right)$ in 60 min extraction process with a yield of $80 \%$ (López et al., 2009).

In conclusion the application of PEF offers the possibility to decrease the energy consumption and a continuous scale up is possible.

\section{Conclusion}

Food processing is a wide field containing many different process steps and techniques based on the principles of process engineering. The industry is searching for new and innovative techniques to improve the quality of the food and to introduce new products with a simultaneous cost reduction. One of the most promising new novel food processing techniques is the application of pulsed electric fields (PEF). This non-thermal treatment is based on the application of pulses with a certain voltage and short duration times ( $\mu \mathrm{s})$ to the product located between two electrodes. The product is located between the electrodes and is exposed to the electric field. The cells and the microorganisms in the product are affected by PEF. Membranes of the cells are destroyed.

For some food processing steps, especially extraction, dehydration and distillation, a rupture of the tissue is required. Many different cell rupturing techniques are available based on mechanical, chemical or thermal treatments, but they often induce a quality loss of the product or the rupture is not sufficient resulting in a low product yield. Using PEF a more efficient rupture of the cells can be achieved. PEF leads to a poration of the cell membrane resulting in a facilitated diffusion out of the cell. The application field has a very wide range such as the extraction yield of juices, oils, sugar and the reduction of drying time 
and distillation time. Industrial scale PEF systems are available and can be implemented in the industry.

Other products as described in the chapter can be analysed as well. Many different studies showed an increased extraction yield, cost reduction and improvement of product quality. Consequently, the PEF process can be used for other product fields, like the extraction of essential oils from plants. Besides products mentioned in that chapter, many other raw materials are eligible for a PEF treatment.

\section{References}

Ade-Omowaye, B. I. O., A. Angersbach, N. M. Eshtiaghi and D. Knorr (2000). Impact of high intensity electric field pulses on cell permeabilisation and as pre-processing step in coconut processing. Innovative Food Science \& Emerging Technologies Vol.1, No.3, pp. 203-209.

Ade-Omowaye, B. I. O., A. Angersbach, K. A. Taiwo and D. Knorr (2001). Use of pulsed electric field pre-treatment to improve dehydration characteristics of plant based foods. Trends in Food Science \& Technology Vol.12, No.8, pp. 285-295.

Ade-Omowaye, B. I. O., N. K. Rastogi, A. Angersbach and D. Knorr (2003). Combined effects of pulsed electric field pre-treatment and partial osmotic dehydration on air drying behaviour of red bell pepper. Journal of Food Engineering Vol.60, No.1, pp. 89-98.

Álvarez, I., J. Raso, A. Palop and F. J. Sala (2000). Influence of different factors on the inactivation of Salmonella senftenberg by pulsed electric fields. International Journal of Food Microbiology Vol.55, No.1-3, pp. 143-146.

Amami, E., A. Fersi, L. Khezami, E. Vorobiev and N. Kechaou (2007a). Centrifugal osmotic dehydration and rehydration of carrot tissue pre-treated by pulsed electric field. LWT - Food Science and Technology Vol.40, No.7, pp. 1156-1166.

Amami, E., A. Fersi, E. Vorobiev and N. Kechaou (2007b). Osmotic dehydration of carrot tissue enhanced by pulsed electric field, salt and centrifugal force. Journal of Food Engineering Vol.83, No.4, pp. 605-613.

Amami, E., E. Vorobiev and N. Kechaou (2006). Modelling of mass transfer during osmotic dehydration of apple tissue pre-treated by pulsed electric field. LWT - Food Science and Technology Vol.39, No.9, pp. 1014-1021.

Angersbach, A. and V. Heinz (1997). Elektrische Leitfähigkeit als Maß des Zellaufschlussgrades von zellulären Materialien durch Verarbeitungsprozesse. Lebensmittelverfahrenstechnik Vol.42, pp. 195-200.

Angersbach, A., V. Heinz and D. Knorr (2000). Effects of pulsed electric fields on cell membranes in real food systems. Innovative Food Science $\mathcal{E}$ Emerging Technologies Vol.1, No.2, pp. 135-149.

Arevalo, P, Ngadi, O. M, Bazhal, I. M, Raghavan and V. G. S (2004). Impact of pulsed electric fields on the dehydration and physical properties of apple and potato slices. Philadelphia, PA, ETATS-UNIS, Taylor \&amp; Francis.

Azeredo, H. M. C. (2009). Betalains: properties, sources, applications, and stability - a review. International Journal of Food Science E Technology Vol.44, pp. 2365-2376. 
Barbosa-Cánovas, G. V., M. M. Góngora-Nieto, U. R. Pothakamury and B. G. Swanson (1999). Biological Principles for Microbial Inactivation in Electric Fields. Preservation of Foods with Pulsed Electric Fields. San Diego, Academic Press: pp. 47-75.

Bazhal, M. and E. Vorobiev (2000). Electrical treatment of apple cossettes for intensifying juice pressing. Journal of the Science of Food and Agriculture Vol.80, No.11, pp. 16681674.

Bazhal, M. I., N. I. Lebovka and E. Vorobiev (2001). Pulsed electric field treatment of apple tissue during compression for juice extraction. Journal of Food Engineering Vol.50, No.3, pp. 129-139.

Bouzrara, H. and E. Vorobiev (2003). Solid/liquid expression of cellular materials enhanced by pulsed electric field. Chemical Engineering and Processing: Process Intensification Vol.42, No.4, pp. 249-257.

Castro, A. J., G. V. Barbosa-Canovas and B. G. Swanson (1993). Microbial Inactivation of Foods by Pulsed Electric Fields. Journal of Food Processing and Preservation Vol.17, pp. 47-73.

Chalermchat, Y., L. Malangone and P. Dejmek (2010). Electropermeabilization of apple tissue: Effect of cell size, cell size distribution and cell orientation. Biosystems Engineering Vol.1 05 pp. 357-366.

Corrales, M., S. Toepfl, P. Butz, D. Knorr and B. Tauscher (2008). Extraction of anthocyanins from grape by-products assisted by ultrasonics, high hydrostatic pressure or pulsed electric fields: A comparison. Innovative Food Science \& Emerging Technologies Vol.9, No.1, pp. 85-91.

Delgado, A. E. and D.-W. Sun (2001). Heat and mass transfer models for predicting freezing processes - a review. Journal of Food Engineering Vol.47, No.3, pp. 157-174.

Dimitrov, D. S. (1984). Electric Field-Induced Breakdown of Lipid Bilayers and Cell Membranes: A Thin Viscoelastic Film Model. No.78, pp. 53-60.

Dimitrov, D. S. (1995). Electroporation and Electrofusion of Membranes. Handbook of Biological Physics, Elsevier Science B. V. Vol.1: pp.851-900

Dobreva, A., F. Tintchev, V. Heinz, H. Schulz and S. Toepfl (2010). Effect of pulsed electric fields (PEF) on oil yield and quality during destillation of white oil-bearing rose (Rosa alba L.). Zeitschrift für Arznei- und Gewürzpflanzen Vol.15, No.3, pp. 127-131.

El-Belghiti, K. and E. Vorobiev (2004). Mass transfer of sugar from beets enhanced by Pulsed electric field. Food and Bioprocess Technology Vol.82, No.C2, pp. 226-230.

Eshtiaghi, M. N. and D. Knorr (2002). High electric field pulse pretreatment: potential for sugar beet processing. Journal of Food Engineering Vol.52, No.3, pp. 265-272.

Fincan, M., F. DeVito and P. Dejmek (2004). Pulsed electric field treatment for solid-liquid extraction of red beetroot pigment. Journal of Food Engineering Vol.64, No.3, pp. 381388.

Glaser, R. W., S. L. Leikin, L. V. Chernomordik, V. F. Pastushenko and A. I. Sokirko (1988). Reversible electrical breakdown of lipid bilayers: formation and evolution of pores. Biochimica et Biophysica Acta (BBA) - Biomembranes Vol.940, No.2, pp. 275-287.

Grimi, N., F. Mamouni, N. Lebovka, E. Vorobiev and J. Vaxelaire (2011). Impact of apple processing modes on extracted juice quality: Pressing assisted by pulsed electric fields. Journal of Food Engineering Vol.103, No.1, pp. 52-61. 
Guderjan, M., P. Elez-Martinez and D. Knorr (2007). Application of pulsed electric fields at oil yield and content of functional food ingredients at the production of rapeseed oil. Innovative Food Science \& Emerging Technologies Vol.8, No.1, pp. 55-62.

Guderjan, M., S. Toepfl, A. Angersbach and D. Knorr (2005). Impact of pulsed electric field treatment on the recovery and quality of plant oils. Journal of Food Engineering Vol.67, No.3, pp. 281-287.

Heinz, V., I. Alvarez, A. Angersbach and D. Knorr (2001). Preservation of liquid foods by high intensity pulsed electric fields--basic concepts for process design. Trends in Food Science E Technology Vol.12, No.3-4, pp. 103-111.

Jalté, M., J.-L. Lanoisellé, N. I. Lebovka and E. Vorobiev (2009). Freezing of potato tissue pretreated by pulsed electric fields. LWT - Food Science and Technology Vol.42, No.2, pp. 576-580.

Janositz, A., A. K. Noack and D. Knorr (2010). Pulsed Electric Fields and their impact on the diffusion characteristics of potato slices. LWT - Food Science and Technology Vol.In Press, Accepted Manuscript, pp.

Knorr, D. and A. Angersbach (1998). Impact of high-intensity electric field pulses on plant membrane permeabilization. Trends in Food Science \& Technology Vol.9, No.5, pp. 185-191.

Lebovka, N. I., M. I. Bazhal and E. Vorobiev (2002). Estimation of characteristic damage time of food materials in pulsed-electric fields. Journal of Food Engineering, No.54, pp. $337 ? 346$.

Lebovka, N. I., M. V. Shynkaryk, K. El-Belghiti, H. Benjelloun and E. Vorobiev (2007). Plasmolysis of sugarbeet: Pulsed electric fields and thermal treatment. Journal of Food Engineering Vol.80, No.2, pp. 639-644.

Lebovka, N. I., N. V. Shynkaryk and E. Vorobiev (2007). Pulsed electric field enhanced drying of potato tissue. Journal of Food Engineering Vol.78, No.2, pp. 606-613.

Lindgren, M., K. Aronsson, S. Galt and T. Ohlsson (2002). Simulation of the temperature increase in pulsed electric field (PEF) continuous flow treatment chambers. Innovative Food Science and Emerging Technologies Vol.3, No.3, pp. 233-245.

Loginova, K. V., N. I. Lebovka and E. Vorobiev (2011). Pulsed electric field assisted aqueous extraction of colorants from red beet. Journal of Food Engineering Vol.106, No.2, pp. 127-133.

Loginova, K. V., E. Vorobiev, O. Bals and N. I. Lebovka (2011). Pilot study of countercurrent cold and mild heat extraction of sugar from sugar beets, assisted by pulsed electric fields. Journal of Food Engineering Vol.102, No.4, pp. 340-347.

López, N., E. Puértolas, S. Condón, J. Raso and I. Alvarez (2009). Enhancement of the extraction of betanine from red beetroot by pulsed electric fields. Journal of Food Engineering Vol.90, No.1, pp. 60-66.

Pliquett, U., R. P. Joshi, V. Sridhara and K. H. Schoenbach (2007). High electrical field effects on cell membranes. Bioelectrochemistry Vol.70, No.2, pp. 275-282.

Puertolas, E., N. Lopez, S. Condón, I. Alvarez and J. Raso (2010). Potential applications of PEF to improve red wine quality. Trends in Food Science \& Technology Vol.21, No.5, pp. 247-255.

Rastogi, N. K., M. N. Eshtiagi and D. Knorr (1999). Accelerated Mass Transfer During Osmotic Dehydration of High Intensity Electrical Field Pulse Pretreated Carrots. Journal of Food Science Vol.64, No.6, pp. 1020-1023. 
Schilling, S., T. Alber, S. Toepfl, S. Neidhart, D. Knorr, A. Schieber and R. Carle (2007). Effects of pulsed electric field treatment of apple mash on juice yield and quality attributes of apple juices. Innovative Food Science E Emerging Technologies Vol.8, No.1, pp. 127-134.

Sharma, S. K., S. J. Mulvaney and S. S. H. Rizvi (2000). Food Process Engineering - Theory and Laboratory Experiments. Canada, John Wiley \& Sons.

Taiwo, K. A., M. N. Eshtiaghi, B. I. O. Ade-Omowaye and D. Knorr (2003). Osmotic dehydration of strawberry halves: influence of osmotic agents and pretreatment methods on mass transfer and product characteristics. International Journal of Food Science \& Technology Vol.38, No.6, pp. 693-707.

Toepfl, S. (2006). Pulsed Electric Fields (PEF) for Permeabilization of Cell Membranes in Food- and Bioprocessing - Applications, Process and Equipment Design and Cost Analysis. Fakultät III - Prozesswissenschaften der Technischen Universität Berlin. Berlin. PhD.

Toepfl, S. and V. Heinz (2011). Pulsed Electric Field Assisted Extraction - A Case Study. Nonthermal processing Technologies for Food. H. Q. Zhang, G. V. Barbosa-Cánovas, V. M. Balasubramaniamet al, Blackwell Publishing Ltd. : pp. 190-200.

Toepfl, S., V. Heinz and D. Knorr (2007). High intensity pulsed electric fields applied for food preservation. Chemical Engineering and Processing Vol.46, No.6, pp. 537-546.

Torreggiani, D. (1993). Osmotic dehydration in fruit and vegetable processing. Food Research International Vol.26, pp. 59-68.

Tsong, T. Y. (1991). Electroporation of cell membranes. Biophysical Journal Vol.60, No.2, pp. 297-306.

Vauck, W. R. A. and H. A. Mueller (2000). Grundoperationen Chemischer Verfahrenstechnik. Stuttgart, Deutscher Verlag für Grundstoffindustrie.

Weaver, J. C. (2000). Electroporation of Cells and Tissues. No.28, pp. 24-33.

Wilhelm, C., M. Winterhalter, U. Zimmermann and R. Benz (1993). Kinetics of pore size during irreversible electrical breakdown of lipid bilayer membranes. Biophysical Journal Vol.64, No.1, pp. 121-128.

Yin, Y. and G. He (2008). A fast high-intensity pulsed electric fields (PEF)-assisted extraction of dissoluble calcium from bone. Separation and Purification Technology Vol.61, No.2, pp. 148-152.

Zhang, Q., G. V. Barbosa-Cánovas and B. G. Swanson (1995). Engineering Aspects of Pulsed Electric Field Pasteurization. Joumal of Food Engineering Vol.25, pp. 261-281.

Zimmermann, U., G. Pilwat, F. Beckers and F. Riemann (1976). Effects of external electrical fields on cell membranes. Bioelectrochemistry and Bioenergetics Vol.3, No.1, pp. 58-83. 


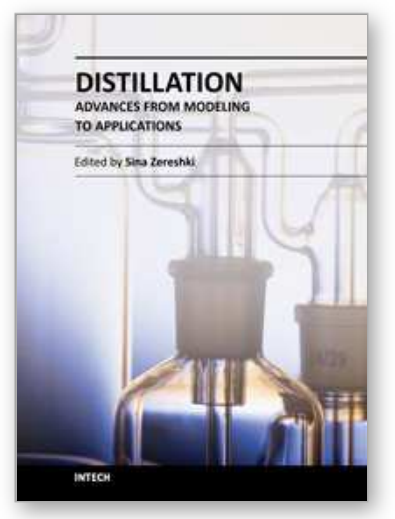

\author{
Distillation - Advances from Modeling to Applications \\ Edited by Dr. Sina Zereshki
}

ISBN 978-953-51-0428-5

Hard cover, 282 pages

Publisher InTech

Published online 23, March, 2012

Published in print edition March, 2012

Distillation modeling and several applications mostly in food processing field are discussed under three sections in the present book. The provided modeling chapters aimed both the thermodynamic mathematical fundamentals and the simulation of distillation process. The practical experiences and case studies involve mainly the food and beverage industry and odor and aroma extraction. This book could certainly give the interested researchers in distillation field a useful insight.

\title{
How to reference
}

In order to correctly reference this scholarly work, feel free to copy and paste the following:

Claudia Siemer, Stefan Toepfl and Volker Heinz (2012). Mass Transport Improvement by PEF - Applications in the Area of Extraction and Distillation, Distillation - Advances from Modeling to Applications, Dr. Sina Zereshki (Ed.), ISBN: 978-953-51-0428-5, InTech, Available from: http://www.intechopen.com/books/distillationadvances-from-modeling-to-applications/mass-transport-improvement-by-pef-applications-in-the-area-ofextraction-and-distillation-

\section{INTECH}

open science | open minds

\section{InTech Europe}

University Campus STeP Ri

Slavka Krautzeka 83/A

51000 Rijeka, Croatia

Phone: +385 (51) 770447

Fax: +385 (51) 686166

www.intechopen.com

\section{InTech China}

Unit 405, Office Block, Hotel Equatorial Shanghai

No.65, Yan An Road (West), Shanghai, 200040, China

中国上海市延安西路65号上海国际贵都大饭店办公楼 405 单元

Phone: +86-21-62489820

Fax: +86-21-62489821 
(C) 2012 The Author(s). Licensee IntechOpen. This is an open access article distributed under the terms of the Creative Commons Attribution 3.0 License, which permits unrestricted use, distribution, and reproduction in any medium, provided the original work is properly cited. 